\title{
Monitoring and Understanding Enterprise Collaboration Platform Outcomes and Benefits Change
}

\author{
Clara S. Nitschke \\ University of Koblenz-Landau \\ cnitschke@uni-koblenz.de
}

\author{
Susan P. Williams \\ University of Koblenz-Landau \\ williams@uni-koblenz.de
}

\begin{abstract}
Enterprise collaboration platforms integrating traditional collaboration tools and enterprise social software are shaped and designed through use. To date, existing research has not studied in any depth how their outcomes and benefits change over time. In this paper, we develop the $\mathrm{MoBeC}$ framework for capturing and monitoring how outcomes and benefits of enterprise collaboration platforms are changing over time. The framework is applied in an empirical setting adopting a longitudinal case study design. The study findings contribute to the deeper understanding of the dynamic and evolving nature of such platforms.
\end{abstract}

\section{Introduction}

In recent years, enterprise collaboration platforms have emerged and changed everyday work in organizations [37]. Such internally-hosted platforms (e.g. IBM Connections, Jive) are large-scale and highly integrated, extending traditional collaboration tools (e.g. shared calendars, document libraries, shared workspaces) by the addition of enterprise social software (ESS) functionality (e.g. wikis, blogs, forums, collaborative tagging, social profiles, activity streams) [29, 71]. When they are introduced into an organization they start as empty shells, they offer a range of components and features but they are not filled with content [45]. Their ESS functionalities provide no in-built purpose of use [61] but afford interpretive flexibility [14], i.e. they are open to multiple, potentially coexisting ways of using the platform [21, 60]. Organizations have different expectations in terms of what they want to gain from the platform and the benefits they want to realize for the business, e.g. improved collaboration, improved communication across silos, faster search for information, or increased productivity [13, 23, 39, 90]. However, once the platform has been introduced and employees start using it, they fill it with content, and experiment with and explore its possibilities to make it fit their needs [45, 58]. Meaning and value emerge over time as the platform is shaped and designed through use [44]. Not all of the expectations organizations have prior to the enterprise collaboration platform implementation actually manifest [4, 32, 78]. Expectations and what may be delivered changes [59:1120, 95:132], and meeting certain expectations may become more/less important to the organization, as the platform is appropriated and used over time [21, 63, 77]. In this way, enterprise collaboration platforms are continuously evolving, and single workspaces within the platform and the platform itself are transforming. For example, an enterprise collaboration platform can evolve from starting out as a mere document-storing tool to a "Social Intranet" to providing a fully integrated digital workplace [92]. Correspondingly, what organizations expect may move from improved global document management to making work faster and easier. The way enterprise collaboration platforms change "[...] is emergent, social, unbounded, and disruptive" [33:99].

There is a growing body of literature on the outcomes of enterprise collaboration platforms and its ESS functionality, i.e. what organisations expect to gain from them (e.g. enabling of rapid exchanges between employees [23]), and their benefits, i.e. the contributions of the outcomes to the business (e.g. speeding up of innovation process [23, 82], or reduced costs of managing information $[34,89])$. Extant studies provide valuable insights into the multiplicity of what may be realized with enterprise collaboration platforms and their ESS, however they are often cross-sectional in nature and conducted at a single point in time, i.e. lacking a temporal view accounting for how outcomes and benefits actually evolve, e.g. [23, 24, 28, 34, 40, 78, $89,94]$. In this study, we address this limitation; our aim is to investigate and understand how enterprise collaboration platform outcomes and benefits change over time. Research has shown that there are also negative outcomes and benefits (disbenefits), e.g. [6, 87, 88], however, this study focuses on the positive outcomes and benefits expected and actually realized. This study contributes to the broader understanding of how enterprise collaboration platforms are changing 
and being shaped through use. It provides researchers and practitioners with a tool to monitor what expectations towards outcomes and benefits of enterprise collaboration platforms and their ESS could have been met to what degree and how the expectations change as the platform is designed through use. The paper is structured as follows: we begin with a review of the existing enterprise collaboration platform and related ESS literature to investigate how (if at all) outcomes and benefits change is addressed in prior research. We then introduce the research approach and develop an analytical framework for monitoring outcomes and benefits change. The framework is used to analyze enterprise collaboration systems outcomes and benefits change in a longitudinal case study. Finally, findings, conclusions and future work directions are presented.

\section{Enterprise collaboration platform out- comes and benefits research}

The literature review is an "essential first step and foundation when undertaking a research project" [3:219]. It provides a basis for our study and examines existing research limitations in the context of understanding benefits change over time. We adopted a critical literature review approach $[51,80]$ to provide a critical reflection on whether and how change of enterprise collaboration platforms and their enterprise social software (ESS) is being addressed. Keyword search was used applying the search terms ('enterprise 2.0' OR 'enterprise social software' OR 'ESS' OR 'enterprise social network' OR 'ESN' OR 'enterprise social media' OR 'social business' OR 'collaboration system' OR 'enterprise collaboration platform' OR 'social collaboration platform') AND ('benefits' OR 'benefits change' OR 'outcomes' OR 'outcomes change'). The primary databases used to identify relevant academic literature were Google Scholar, Springerlink, ACM Digital Library, JSTOR, IEEE Explore, Wiley Online Library. The search process was extended by backward and forward snowball sampling [93] to identify further potentially relevant literature. The complete search process yielded 65 papers that were published between 2008 and 2019 and addressed outcomes and benefits of single social software features (e.g. microblogs, wikis) or integrated platforms comprising a set of social software features. Each literature item was added to a literature spreadsheet and critically assessed with the following criteria: metadata (e.g. data source, literature type, publication year, authors), focus topic, research aim and method, timing of data collection, use of terminology for outcomes/benefits, addressing of outcomes/benefits change, conceptualization/theorization of outcomes/benefits. The analysis of the literature allowed us to identify different streams of research and related strengths and limitations as summarized below.

Associations of outcomes and benefits. A range of empirical studies propose and test structural models with outcomes and benefits measures and their associations (antecedents and impacts). The models often build on and extend existing and widely used IS benefits models and theories, such as the updated DeLone and McLean information success model [12], e.g. [34, 54], the Technology Acceptance Model (TAM) [10] or the Unified Theory of Acceptance and Use of Technology (UTAUT) [83], e.g. [19, 20, 82, 86]. Outcomes and benefits may be specific to one type (e.g. decision making performance [29], employee innovation [31]) or consolidated into one item (e.g. relative advantage [32], net benefits [34], value [8, 39]), thus 'black boxing' the multifacetedness of outcomes and benefits. Such research is typically based on large sample sizes and aims to offer generalizations for enterprise collaboration platform projects. While this research stream provides important insights into general success factors and use intentions of enterprise collaboration platforms, the models and corresponding constructs are prescriptive and typically defined before the surveybased data collection, i.e. the outcomes and benefits and their measurement are specified a priori. In this way, outcomes and benefits change cannot be accounted for appropriately [61, 64].

Identification and classification of outcomes and benefits. There is a growing body of literature focusing on the identification and classification of outcomes and benefits, e.g. [2, 24, 38, 78, 89, 96]. Often, using case studies as either primary or secondary data. For example, Wehner et al. [89] review 37 case study articles to identify 99 distinct benefits and classify them into the traditional IT capabilities as presented by Davenport and Short [9]. Archer-Brown and Kietzmann [2] analyze 39 case studies, including market reports and cases published by software vendors, to identify outcomes and benefits and group them according to intellectual capital dimensions. Other studies employ cross-case snapshot analyses to identify and compare perceived or realized outcomes and benefits of a small set of ESS and enterprise collaboration platform projects, e.g. [78, 94]. Only a few studies aim to classify outcomes and benefits to different times. For instance, Dittes and Smolnik [13] assign outcomes to three different impact levels (process, employee, organizational) that are generally achieved over time, e.g. if knowledge sharing behavior (employee level outcome) is adopted and leveraged by an increasing number of employees then it may have productivity impacts on the whole of the organization (organizational level outcome). In contrast, Herzog and Steinhüser [23] map outcomes and 
benefits onto different stages of the ESS-enabled innovation process.

This research stream sheds light on the variety and range of outcomes and benefits of different kinds, and in part increases awareness that outcomes and benefits may be realized at different times of the project. However, this stream does not yet account for how the enterprise collaboration platform outcomes and benefits themselves actually change, where their importance may change and also where and how unanticipated and intended outcomes and benefits may emerge [69].

Measurement of outcomes and benefits. Enterprise collaboration platforms offer many different opportunities to organizations [50], but there is often uncertainty in terms of whether expected outcomes and benefits are achieved. Based on the organizations' need to justify Information Technology (IT) investments, researchers have started to develop and use outcomes and benefits metrics to provide evidence for the enterprise collaboration platform project successes. Different measurement approaches are used, including logfile analysis, process analysis, social network analysis, content analysis, sentiment analysis or user interviews and surveys [27, 57]. Typically, different uses of the platform (e.g. consumptive use, contributive use, hedonic use, social use) [30], usage frequency of different activities (e.g. visiting, contributing, creating, following), e.g. [22, 41, 75, 76], and related user types (e.g. creator, contributor, lurker) [72] are measured. Muller et al. [42] propose the return on contribution (ROC) construct, a ratio between production and consumption, and costs and benefits, respectively. While they use ROC to show how the ROC value changes over time, the measurement approach is rather simplistic in that it does not acknowledge the richness of benefits. Other measures are more targeted at revealing the value of platform usage and are largely result-oriented, e.g. reduced time worked with documents [57], number of ideas [27, 57], reduction of emails [27].

Use cases as outcomes. This stream of research identifies, catalogues and describes resulting use cases as outcomes of and basis for value from ESS and enterprise collaboration platforms, such as information sharing, work coordination, event management, or team organization, e.g. [18, 59, 65, 66]. Glitsch and Schubert [18:867] describe use cases as "descriptions of business activities on a high level that support collaborative tasks". This stream does not focus on how use cases change but focuses on the enterprise collaboration platforms' interpretive flexibility in that they offer diverse possibilities for usage. Often, use cases are identified from ESS and enterprise collaboration platform cases via content analyses and related coding.

Technology affordances and resulting outcomes. A small set of the analyzed literature deals with out- comes of affordances of ESS and enterprise collaboration platforms, e.g. $[25,35,81]$. According to a technology affordance perspective technology is perceived as affording different possibilities for action and ways of using it [36, 84]. Research in this stream typically uses or builds on case study research and illustrates that enterprise collaboration platform outcomes are not just there and the same for all organizational members and groups. For example, Leidner et al. [35] conduct a single case study to investigate first-order affordances, e.g. interacting with peers, and second-order affordances, e.g. building relationships with peers, and their outcomes, e.g. productivity enhancement. In their study, the concept of generative mechanisms is used to explain how affordances lead to outcomes. Building on eight years of data collection, the findings suggest the intertwining of affordances, actors and outcomes and that they may create new affordances and outcomes for new actors. Similarly, adopting a relational approach, Treem and Leonardi [81] assume that technological affordances can alter across different contexts. However, the identified studies of this stream do not yet address how outcomes and benefits change over time.

The literature analysis reveals different research streams and shows a growing interest in outcomes and benefits. Over time, the unit of analysis shifted from single social software tools (e.g. wikis, social networks, microblogs), e.g. [42, 65, 77, 78, 95], to more integrated platforms, e.g. [24, 27, 31, 41, 50]. In the studies, we found a lack of clarity in the terminology of outcomes and benefits. In most cases, both terms are not clearly defined, and they are used interchangeably with the terms impacts, success, opportunities, or advantages to describe what organizations can get out of ESS and enterprise collaboration platforms. In order to study how enterprise collaboration platform outcomes and benefits change, there is a need to establish a common understanding of what outcomes and benefits mean. The current literature points to the importance of studying the evolution of ESS / enterprise collaboration platforms, e.g. $[4,32,77,78]$, but has to date, not incorporated this evolutionary perspective in any depth. In this paper we address this limitation and the call for more longitudinal studies of enterprise collaboration platforms and change [13, 40, 77].

Specifically, our research objectives are i) to develop a framework and method for capturing and monitoring enterprise collaboration platform outcomes and benefits change, and ii) to apply the derived framework in an empirical setting to examine the evolving nature of enterprise collaboration platforms and identify how their outcomes and benefits change over time. 


\section{Method}

In this study, we follow a qualitative approach [85] to develop a framework for capturing and monitoring how outcomes and benefits of enterprise collaboration platforms change. We then apply the framework to examine how outcomes and benefits are changing in a case organization [49]. The research is structured into two research phases. Phase 1: Development of the framework: The goal of this phase is to examine existing IS benefits frameworks and methods and their support for capturing and monitoring outcomes and benefits change, and if necessary, extend them to meet the evolutionary nature of enterprise collaboration platforms. This phase consists of three research steps. In the first step we examined studies in the wider IS benefits literature (IS/IT investment studies [e.g. 7, 26, 55], IS success measurement [e.g. 11, 53, 73], IS benefits classification and measurement [e.g. 44, 47, 74], benefits realization management (BRM) [e.g. 16, 52, 56]) to identify whether and how the aspect of time is being addressed in the study of outcomes and benefits. Of this work BRM addresses the time aspect, having its origin in the study of IS-enabled change and the management of the realization of benefits over time. Therefore, in the second step, we focused specifically on BRM methods and frameworks to examine the degree to which they incorporate outcomes and benefits change. We identified two frameworks appropriate to study outcomes and benefits change of enterprise collaboration platforms as they encompass a temporal flow of outcomes and benefits and their relation to organizational changes and required capabilities to deliver change. The two selected frameworks are the Office of Government Commerce (OGC)'s benefits realization framework [48], and the benefits dependency network (BDN) [52,87]. In the third step we investigated the suitability of the two frameworks by using them to analyse three case studies of enterprise collaboration platform implementation projects. The studies, conducted in three different organizations are part of our wider university-industry research program [91]. Developed using the eXperience method $[68,70]$ the cases have a uniform structure, where the second section includes data captured about the reasons for the project and project expectations including expected outcomes and benefits. Through an iterative, qualitative analysis [17], we used the two frameworks to structure and visualize the outcomes and benefits presented in the case studies. In doing so we integrate the theoretical and practical findings about outcomes and benefits, and use them to derive the Monitoring Benefits Change (MoBeC) framework applied in Phase 2 to examine outcomes and benefits change in greater depth. Phase 2: Application of the framework: The goal of phase 2 is to use the $\mathrm{MoBeC}$ framework to examine one specific enterprise collaboration platform project in depth. The objective is to investigate the expected and realized outcomes and benefits at two different points in time to provide an over-time comparison within one case (a "diachronic" study [79]) to show change over time. The case was selected for two reasons: first, the enterprise collaboration platform project was just beginning, enabling us to study it from the start, and, second, the platform was being introduced bottom-up, which is typical for enterprise collaboration platforms [61, 62]. Data was collected, using the developed framework as an interview guideline, through two seven-hour semi-structured face to face interviews with key informants with responsibility for the platform (first interview: 06/2016, second interview: 11/2018). The data collected about outcomes and benefits were then visualized employing the developed framework.

\section{MoBeC framework and instantiation}

The OGC's benefits realization framework [48:79] provides the basis for our Monitoring Benefits Change (MoBeC) framework (Figure 1). In terms of benefits realization it considers both organizational competence and the IS/IT implementation itself. In the OGC's benefits realization framework [48:79], outcomes are "new desired operational states", such as "fulfilling and charging for web-based orders", which deliver benefits. Benefits are described as "the measurable improvement resulting from an outcome perceived as an advantage by one or more stakeholders", for example "increased sales revenues" [48:79]. Following this definition, benefits capture what an organization may gain from achieving outcomes. In the attempt to define paths to the realization of outcomes and benefits, the OGC [48] additionally introduces the concepts of outputs and capabilities that need to be in place before outcomes can even be achieved. Specifically, capabilities "enable the new operating state" [48:79] by utilizing and transforming outputs being developed from planned activities and often these are technical or functional deliverables (e.g. specific social software components). In this way, the OGC suggests a temporal flow from outputs to benefits. This flow is adopted by MoBeC. As previous research, e.g. [43], and our case analyses reveal, not all resulting benefits are measurable and tangible. Therefore, $\mathrm{MoBeC}$ extends the OGC framework by making the distinction between the benefit description, and the benefit measure. All benefits must have a benefit description that provides an explanation of an observable change and may have a benefit measure, a specific metric or evidence for that change. 


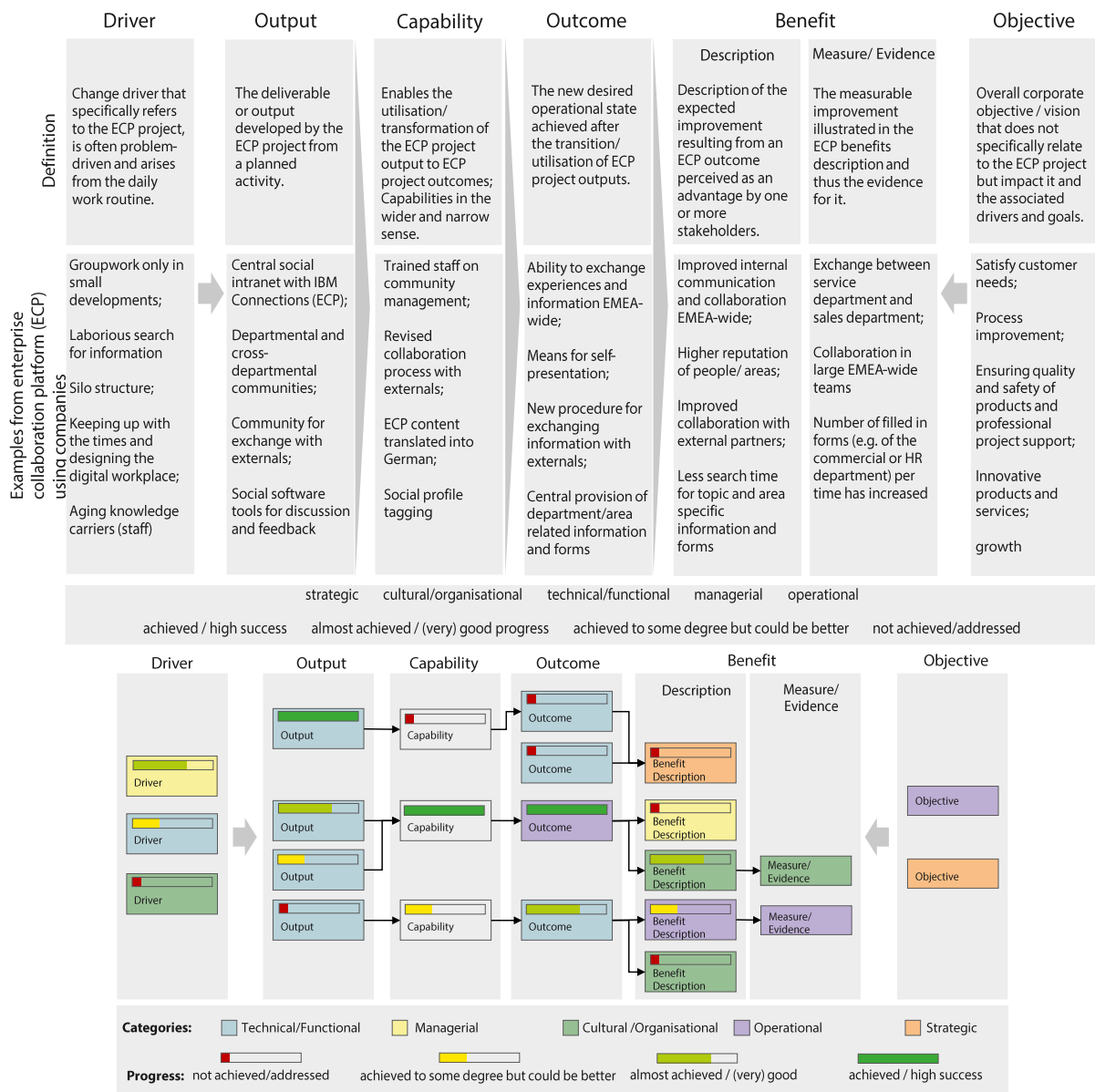

Figure 1: MoBeC framework (elements \& instantiation template)

The MoBeC framework also draws from the benefits dependency networks (BDN) proposed by Ward, Peppard and colleagues [52, 87], in two ways. First, we incorporate the concept of objectives, and, second, we visualize dependencies in $\mathrm{MoBeC}$ 's instantiation template. Peppard et al. [52] distinguish between a) means (IS/IT enablers, similar to the OGC's outputs), b) ways (enabling changes as one-off changes, similar to the OGC's capabilities, and business changes as permanent changes, similar to the OGC's outcomes), and c) ends (benefits and investment objectives).

From the three case studies on the enterprise collaboration platform implementation projects we identified that global more enduring corporate objectives (e.g. process improvement, productivity improvement, innovative products and services) may have an impact on the benefits (e.g. improved cross-site collaboration or enhanced decision making) organizations want to achieve with the collaboration platform. Such objectives do not specifically relate to the introduction of the platform but may impact the benefits organizations expect to achieve with the platform. To model this relation, they are positioned on the right side of $\mathrm{MoBeC}$ close to the benefits. However, the case study analysis also revealed that there are project specific drivers (referred to as investment objectives by Ward and Daniel [87:130] and Peppard et al. [52:12]) that may be opportunity-driven (e.g. keeping up with the times and designing the digital workplace) or problem-driven (e.g. aging knowledge carriers (staff)). Because such drivers steer the platform implementation and path from related outputs to expected outcomes and benefits, they are positioned on the left side of $\mathrm{MoBeC}$.

In contrast to the OGC's benefits realization framework and BDN, the MoBeC framework and related instantiation template does not only capture the outcomes and benefits that are expected but also to what degree they are achieved if a corresponding measure is present. In line with Ward and Daniel [87:129-130], we view subjective measures related to perceptions of the achievement level acceptable, as there is seldom objective evidence for it in enterprise collaboration platform projects [22]. In order to gather the progress of achievement, employees with project responsibility must rate their achievement on a scale from 1 (not achieved/addressed) to 4 (achieved / high success) and provide objective evidence if available (e.g. employees from different departments are mem- 
bers of the same community where they interact with each other as visible in the event database for the platform [71]). Since enterprise collaboration platforms are emerging over time, it is necessary to collect outputs, capabilities, outcomes and benefits at regular points in time. The gathered outputs, outcomes, and benefits etc. can be assigned to different dimensions (e.g. managerial, operational, strategic) following our case examination and existing benefits classifications [67, 68, 74]. Capabilities cannot be easily assigned to a single category as they are more complex, requiring learning and reflection entangled in the specifics of the organisational context $[1,15]$.

\section{Enterprise collaboration platform case}

\subsection{Case background}

The case company pseudonymized as Chemical Products Manufacturer 03 (CPM03) manufactures and supplies construction chemical products and industrial sealants and adhesives to businesses. Based in Germany and with 1,100 employees it is one of the largest subsidiaries of its globally active Swiss parent company. The introduction of IBM Connections as part of the company's new global social intranet was decided bottom-up in the parent company of CPM03. It should be operated as a cloud solution (IBM SmartCloud) and be accessible company wide. In 2014, the global roll out began, i.e. the platform was introduced successively in all subsidiaries of the parent company. At CPM03, the communication and advertising area was tasked with the introduction of the platform. However, due to personnel shortage in this area, CPM03 was the last subsidiary to officially introduce IBM Connections. In June 2016, a project team from the communication and advertising area plus staff from the Information Technology (IT) department began actively promoting the enterprise collaboration platform and supporting its introduction on a voluntary use basis. Like all other subsidiaries, CMP03 is free to decide on specific project and change management measures and activities, the goals they want to achieve with the collaboration platform and how they design platform communities (workspaces) for their own purposes.

\subsection{Application of the MoBeC framework}

In 2016, CMP03 placed special emphasis on static uses of the collaboration platform, i.e. provision and consumption of data and information was seen as key.

While a variety of different outcomes and benefits were expected, the collaboration platform was specifi- cally envisioned as a means for presenting different people, departments and areas of the company (providing an overview of them, their workflows \& products) through open platform communities (workspaces). This was expected to raise awareness about the different people, departments and areas and increase their reputation within the company. Also, it was expected that departments and areas could use their communities to provide people/department/area related information and business forms (e.g. work contract form provided by the human resources area) to reduce their search time. Previously information and forms were largely reached via network drive directories, e-mail, telephone or personal contact. Often, the search process was laborious and not always successful. In terms of the interaction between different people from different areas it was also hoped that the collaboration platform supports communication and collaboration across business areas particularly within Germany. Two years later, in 2018, the collaboration platform is described as successfully integrated into the digital workplace, has become background [5], "[The collaboration platform] is now everyday life among many, many departments" (Project Manager, Communication and Marketing, 22/11/2018). The different departments and areas have successfully built their own communities, however a new central outcome emerged. Now the organization of meetings and events and project work via the collaboration platform have become a priority. Here, people from different areas are involved and rely on their joint more dynamic and interactive work, "I and my colleagues are so used to it that if, after two or three weeks, the meeting minutes are not in there somewhere, someone is saying 'you've forgotten something'; [It] is really used as a work tool as well" (Head of IT, 22/11/2018). However, the organization of meetings/events and project work are mainly considered valuable when people from different sites of CMP03, the Swiss parent company and its different subsidiaries come together, i.e. communication and collaboration across areas happens largely organization-wide and less within the German case company.

Figure 2 shows the MoBeC framework capturing the enterprise collaboration platform project status from 2016 (top) and from 2018 (bottom) for CMP03. In the following, the changes in enterprise collaboration platform outcomes and benefits are elaborated on in more detail. Because of the special situation of the studied case, where the platform introduction was initiated by the parent company, the drivers were split into main drivers (particularly of the global roll-out) and supporting drivers (present in the case company itself) of the enterprise collaboration platform project. 


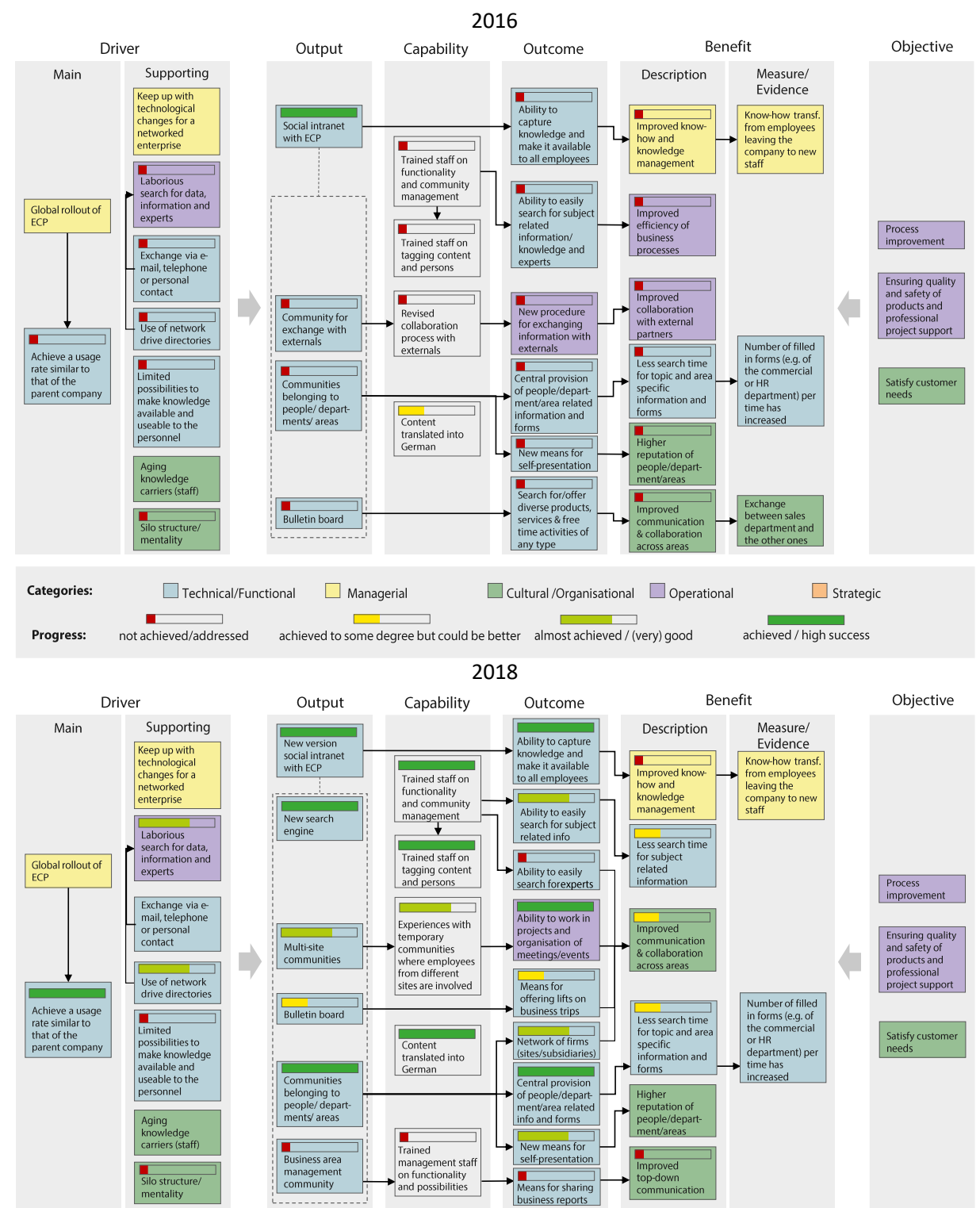

Figure 2: Monitoring outcomes \& benefits change at CMP03

Since 2016 there have been significant changes. CMP03 made progress in terms of the achievement and addressing of different drivers (e.g., there has been good progress in addressing the laborious search for data, information and expert), outputs (e.g., communities belonging to people/departments/areas have successfully been built), capabilities (e.g., the translation of relevant platform content is complete), outcomes (e.g. the majority of the platform users have acquired the ability to easily search for subject related information), and benefits (e.g., communication and collaboration across areas could be achieved to some degree). Furthermore, new outputs, capabilities, outcomes and benefits emerged, some of these have not been achieved/ addressed yet (e.g. the output of a business area management community) and others are already considered as highly successful (e.g., the outcome of the ability to work in projects and organization of meetings/events). In contrast, other outputs, capabilities and benefits disappeared, they are no longer of relevance. We identified that (a) whole paths from output to benefit may disappear, (b) benefits may stay the same but be achieved through different than previously anticipated paths of outputs, capabilities and outcomes, and (c) outputs may stay the same but lead to unanticipated outcomes and benefits, as shown below.

(a) The path from a community for the exchange with externals (output) to a revised collaboration process with externals (capability) to a new procedure for exchanging information with externals (outcome) to improved collaboration with external partners (benefit description) dissolved. Due to privacy regulations ex- 
change with external partners via the enterprise collaboration platform would require building and maintaining an enterprise collaboration platform community for each partner (e.g. a printing company) CMP03 is working with. Instead, the case company has established the usage of an alternative cloud file sharing software solution to exchange files with external partners.

(b) A benefit that stayed the same but is now, in 2018 , expected to be achieved via a different path of outputs, capabilities and outcomes is improved communication and collaboration across areas. As a key contributing outcome to this benefit the ability to work in projects and the organization of meetings/events emerged. Project work and the organization of meetings/events is implemented through communities with members from different company sites (output) and based on the enterprise collaboration platform users' experiences with such communities (capability).

(c) Some of the outcomes and benefits are not of importance anymore. For example, while CMP03 initially wanted to build a bulletin board (output) on the platform to search for and offer diverse products, services and free time activities (outcome) to foster improved communication and collaboration across areas (benefit description), meanwhile the bulletin board is used occasionally to offer lifts on business trips (new unanticipated outcome).

The MoBeC framework has enabled us to successfully capture, analyze and visualize how these outcomes and benefits change over time.

\section{Conclusion and Outlook}

In this paper, we develop the MoBeC framework for capturing and monitoring enterprise collaboration platform outcomes and benefits change. We apply the framework in an empirical setting adopting a longitudinal study design. Enterprise collaboration platforms differ from transactional information systems, e.g. Enterprise Resource Planning systems, as they offer interpretive flexibility and are shaped and designed through use. Expected and realized outcomes and benefits of enterprise collaboration platforms change over time. As organizations use their collaboration platform, they collect experiences and recalibrate what they want to gain from the platform. Our empirical in-depth case analyzed using MoBeC shows that organizations develop capabilities that cannot be easily visualized as connectors between specific outputs and outcomes, as they are complex and relational. Work is now under way to draw attention to the building of digital transformation competencies and capabilities [46]. This includes the study of how organizations deal with challenges in terms of unanticipated negative outcomes and benefits enabling or constraining the delivery of desired outcomes and benefits. The findings from our ongoing research are expected to serve as key input for the refinement of the $\mathrm{MoBeC}$ framework and related theorizations about outcomes and benefits and contribute to the further understanding of how enterprise collaboration platforms transform. Part of our current research is the development and testing of an interactive data visualization that presents the change pathways and animates the evolution of change over time.

\section{References}

[1] Andreu, R., and C. Ciborra, "Organisational learning and core capabilities development: The role of IT”, JSIS 5(2), 1996, pp. 111-127.

[2] Archer-Brown, C., and J. Kietzmann, "Strategic knowledge management and enterprise social media", JKM 22(6), 2018, pp. 1288-1309.

[3] Baker, M.J., "Writing a literature review", Market. Rev. 1(2), 2000, pp. 219-247.

[4] Bala, H., A.P. Massey, J. Rajanayakam, and C.J. Hsieh, "Challenges and outcomes of enterprise social media implementation: Insights from Cummins, Inc.", HICSS, (2015).

[5] Bowker, G.C., K. Baker, F. Millerand, and D. Ribes, "Toward Information Infrastructure studies: Ways of knowing in a networked environment", In J. Hunsinger, L. Klastrup and M. Allen, eds., International Handbook of Internet Research. Springer, Dordrecht, 2010, 97-117.

[6] Breese, R., "Benefits realisation management: Panacea or false dawn?", IJPM 30(3), 2012, pp. 341-351.

[7] Brynjolfsson, E., and L. Hitt, "Paradox lost? Firm-level evidence of high returns to information systems spending", Management Science 42(4), 1993, pp. 541-558.

[8] Chin, C.P.Y., N. Evans, and K.K.R. Choo, "Exploring Factors Influencing the Use of Enterprise Social Networks in Multinational Professional Service Firms", J Org Comp Elect Com 25(3), 2015, pp. 289-315.

[9] Davenport, T.H., and J.E. Short, "The new industrial engineering: information technology and business process rede-sign”, Sloan Management Review 31(4), 1990.

[10] Davis, F.D., "Perceived usefulness, perceived ease of use, and user acceptance of information technology", MISQ 13(3), 1989, pp. 319-340.

[11] DeLone, W.H., and E.R. McLean, "Information systems success: The quest for the dependent variable", ISR 3(1), 1992, pp. 60-95.

[12] DeLone, W.H., and E.R. McLean, "The DeLone and McLean Model of Information Systems Success: A Ten-Year Update", JMIS / Spring 19(4), 2003, pp. 9-30.

[13] Dittes, S., and S. Smolnik, "Why Are We Doing This Again? Towards Uncovering the Outcome Perspective of Enterprise Social Software Use", ECIS, (2017).

[14] Doherty, N.F., C.R. Coombs, and J. Loan-Clarke, "A reconceptualization of the interpretive flexibility of information technologies: Redressing the balance between the social and the technical”, Eur J Inf Syst 15(6), 2006, pp. 569-582.

[15] Dourish, P., "What we talk about when we talk about context”, Pers Ubiquit Comput 8(1), 2004, pp. 19-30. 
[16] Eisenhardt, K.M., and C. Bird, "Process and reality in information systems benefit analysis", Science, 2001.

[17] Glaser, B.G., "The Constant Comparative Method of Qualitative Analysis", Soc Probl 12(4), 1965, pp. 436-445.

[18] Glitsch, J.H., and P. Schubert, "IRESS: Identification of Requirements for Enterprise Social Software", CENTERIS, (2017).

[19] Günther, O., H. Krasnova, D. Riehle, and V. Schöndienst, "Modeling Microblogging Adoption in the Enterprise", AMCIS, (2009).

[20] Harden, G., "Knowledge Sharing in the Workplace: A Social Networking Site Assessment", HICSS, (2012).

[21] Herzog, C., and A. Richter, "Use Cases as a Means to Support the Appropriation of Enterprise Social Software", HICSS, (2016), 4071-4080.

[22] Herzog, C., A. Richter, M. Steinhüser, et al., "Methods and Metrics for Measuring the Success of Enterprise Social Software: What we can learn from practice and vice versa", ECIS, (2013), 1-12.

[23] Herzog, C., and M. Steinhüser, "The Impacts of Enterprise Social Software on the Innovation Process", EDOC, (2016), 59-68.

[24] Holtzblatt, L., J.L. Drury, D. Weiss, L.E. Damianos, and D. Cuomo, "Evaluating the Uses and Benefits of an Enterprise Social Media Platform”, JSMO I(1), 2013, pp. 1-21.

[25] Kane, G.C., "Enterprise social media: Current capabilities and future possibilities", MISQE 14(1), 2015, pp. 1-16.

[26] King, J., and E.L Schrems, "Cost-benefit analysis in Information Systems development and operation", ACM Computing Surveys 10(1), 1978, pp. 19-34.

[27] Kirchner, K., and L. Razmerita, "Managing the Digital Knowledge Work with the Social Media Business Value Compass", HICSS, (2019), 6438-6447.

[28] Kügler, M., S. Dittes, S. Smolnik, and A. Richter, "Connect Me! Antecedents and Impact of Social Connectedness in Enterprise Social Software", BISE 57(3), 2015, pp. 181-196. [29] Kügler, M., and S. Smolnik, "Just for the fun of it? Towards a model for assessing the individual benefits of employees' enterprise social software usage", HICSS, (2013).

[30] Kügler, M., and S. Smolnik, "Uncovering the phenomenon of employees' enterprise social software use in the postacceptance stage - proposing a use typology", ECIS, (2014).

[31] Kügler, M., S. Smolnik, and G. Kane, "What's in IT for employees? Understanding the relationship between use and performance in enterprise social software", JSIS 24(2), 2015, pp. 90-112.

[32] Kügler, M., S. Smolnik, and P. Raeth, "Determining the Factors Influencing Enterprise Social Software Usage: Development of a Measurement Instrument for Empirical Assessment", HICSS, (2013), pp. 3635-3644.

[33] Kumar, V., J. Loonam, J.Allen, and S. Sawyer, "Exploring enterprise social systems \& organisational change: Implementation in a digital age", JIT 31(2), 2016, pp. 97-100. [34] Lehner, F., M. Langbauer, and N. Amende, "Measuring success of enterprise social software", i-KNOW'14, (2014).

[35] Leidner, D.E., E. Gonzalez, and H. Koch, "An affordance perspective of enterprise social media and organizational socialization", JSIS 27(2), 2018, pp. 117-138.

[36] Leonardi, P.M., "When flexible routines meet flexible technologies: Affordance, constraint, and the imbrication of human and material agencies", MISQ 35, 2011, pp. 147-167.
[37] Leonardi, P.M., M. Huysman, and C. Steinfield, "Enterprise social media: Definition, history, and prospects for the study of social technologies in organizations", JCMC 19(1), 2013, pp. 1-19.

[38] Majumdar, A., S. Krishna, and P. Bjorn, "Managers' perceptions of social software use in the workplace: identifying the benefits of social software and emerging patterns of its use", AMCIS, (2013).

[39] Mäntymäki, M., and K. Riemer, "Information, Ideas and Input: The Value of Enterprise Social Networks", ACIS, (2014), 1-11.

[40] Mäntymäki, M., and K. Riemer, "Enterprise social networking: A knowledge management perspective", IJIM 36(6), 2016, pp. 1042-1052.

[41] De Michele, R., T. Fabbri, and C. Canali, "Social Technologies for the Workplace: Metrics Proposal for Adoption Assessment", GOODTECHS 2019, (2018).

[42] Muller, M.J., J. Freyne, C. Dugan, D.R. Millen, and J. Thom-Santelli, "Return On Contribution (ROC): A Metric for Enterprise Social Software", In I. Wagner, H. Tellioğlu, E. Balka, C. Simone and L. Ciolfi, eds., ESCW 2009. Springer, London, 2009, 143-150.

[43] Murphy, K.E., and S.J. Simon, "Intangible benefits valuation in ERP projects", ISJ 12(4), 2002, pp. 301-320.

[44] Nah, F.F., J.L. Lau, and K. Jinghua, "Critical factors for successful implementation of enterprise systems", Benchmarking: An international journal 7(3), 2001, pp. 285-296.

[45] Nitschke, C.S., and S.P. Williams, "Traces of design activity: the design of coordination mechanisms in the shaping of enterprise collaboration systems", CENTERIS, (2018). [46] Nitschke, C.S., S.P. Williams, and P. Schubert, "A Multiorganisational Study of the Drivers and Barriers of Enterprise Collaboration Systems-Enabled Change”, WI, (2019).

[47] O'Leary, D., "Enterprise resource planning (ERP) systems:An empirical analysis of benefits",JETA 1,2004, 63-72.

[48] OGC, Managing successful programmes, The Stationery Office (TSO), London, 2011.

[49] Orlikowski, W.J., and J.J. Baroudi, "Studying Information Technology in organizations: Research approaches and assumptions", ISR 2(1), 1991, pp. 1-31.

[50] Osch, W. van, C. Steinfield, and B. Balogh, "Enterprise social media: Challenges and opportunities for organizational communication and collaboration", HICSS, (2015), 763-722. [51] Paré, G., M. Trudel, M. Jaana, and S. Kitsiou, "Synthesizing information systems knowledge: A typology of literature reviews", Inform Manage 52(2), 2015, pp. 183-199.

[52] Peppard, J., J. Ward, and E. Daniel, "Managing the Realization of Business Benefits from IT Investments", MISQE 6(1), 2007, pp. 1-12.

[53] Petter, S., W. Delone, and E. Mclean, "No Measuring information systems success: models, dimensions, measures, and interrelationships”, EJIS 17(3), 2008, pp. 236-263.

[54] Raeth, P., S. Smolnik, N. Urbach, and C. Zimmer, "Towards Assessing the Success of Social Software in Corporate Environments", AMCIS, (2009).

[55] Remenyi, D., F. Bannister, and A. Money, The effective measurement and management of ICT cost and benefits, Elsevier, Oxford, UK, 2007.

[56] Remenyi, D., T. White, and M. Sherwood-Smith, Achieving Maximum Value From Information Systems - A Process Approach, John Wiley, Chichester, 1997. 
[57] Richter, A., J. Heidemann, M. Klier, and S. Behrendt, "Success Measurement of Enterprise Social Networks", WI, (2013), pp. 1-15.

[58] Richter, A., C. Hetmank, J. Klier, M. Klier, and M. Müller, "Enterprise social networks from a manager's perspective", HICSS, (2016), 4242-4251.

[59] Richter, A., S. Mörl, M. Trier, and M. Koch, "Anwendungsszenarien als Werkzeug zur (V)Ermittlung des Nutzens von Corporate Social Software", WI, (2011), 1104-1113.

[60] Richter, A., and K. Riemer, "Corporate social networking sites - Modes of use and appropriation through coevolution", ACIS, (2009), 722-732.

[61] Richter, A., and K. Riemer, "Malleable end-user software", BISE 5(3), 2013, pp. 195-197.

[62] Richter, A., A. Stocker, and M. Koch, "Exploration \& Promotion: Einführungsstrategien von Corporate Social Software", WI, (2011), 97-106.

[63] Riemer, K., and R.Johnston, "Place-making: A phenomenological theory of technology appropriation", ICIS, (2012).

[64] Riemer, K., P. Overfeld, P. Scifleet, and A. Richter, "Eliciting the anatomy of technology Appropriation Processes: A Case Study in enterprise social media", ECIS, (2012).

[65] Riemer, K., and A. Richter, S.O.C.I.A.L. - Emergent Enterprise Social Networking Use Cases: A Multi Case Study Comparison, 2012. Business Information Systems Working Paper Series, 2012.

[66] Schubert, P., and J.Glitsch, "Use cases and collaboration scenarios: How employees use socially-enabled enterprise collaboration systems (ECS)", IJISPM 4(2), 2016, pp. 41-62. [67] Schubert, P., and S.P. Williams, "An Extended Framework for Comparing Expectations and Realized Benefits of Enterprise Systems Implementations", AMCIS, (2009).

[68] Schubert, P., and S.P. Williams, "A framework for identifying and understanding enterprise systems benefits", BPMJ 17(5), 2011, pp. 808-828.

[69] Schubert, P., and S.P. Williams, "The case of UniConnect - The shaping of an academic collaboration platform", MKWI, (2016), 327-338.

[70] Schubert, P., and R. Wölfle, "The eXperience methodology for writing IS case studies”, AMCIS, (2007), 1-15.

[71] Schwade, F., and P. Schubert, "Social Collaboration Analytics for Enterprise Collaboration Systems: Providing Busi-ness Intelligence on Collaboration Activities", HICSS, (2017), 401-410.

[72] Schwade, F., and P. Schubert, "Developing a User Typology for the Analysis of Participation in Enterprise Collabo-ration Systems Literature Review: User Types", HICSS, (2019), 460-469.

[73] Seddon, P.B., "A respecification and extension of the DeLone and McLean model of IS success", ISR 8(3), 1997, pp. 240-253.

[74] Shang, S., and P.B. Seddon, “Assessing and managing the benefits of enterprise systems: The business manager's perspective", ISJ 12(4), 2002, pp. 271-299.

[75] Stocker, A., and J. Müller, "Exploring Factual and Perceived Use and Benefits of a Web 2.0-based Knowledge Management Application", i-Know'13, (2013).

[76] Stocker, A., and J. Müller, "Exploring use and benefit of corporate social software", J of Syst \& IT 18(3), 2016, pp. 277-296.
[77] Stocker, A., A. Richter, P. Hoefler, and K. Tochtermann, "Exploring appropriation of enterprise wikis: A multiple-case study", CSCW 21(2-3), 2012, pp. 317-356.

[78] Stocker, A., and K. Tochtermann, "Enterprise Wikis Types of Use, Benefits and Obstacles: A Multiple-Case Study", In A. Fred, J.L.G. Dietz, K. Liu and J. Filipe, eds., Knowledge Discovery, Knowledge Engineering and Knowledge Management. IC3K 2009. Communications in Computer and Information Science. Springer, Berlin, 2011.

[79] Thomas, G., "A typology for the case study in social science following a review of definition, discourse, and structure", Qualitative Inquiry 17(6), 2011, pp. 511-521.

[80] Torraco, R.J., "Writing Integrative Reviews of the Literature", IJAVET 7(3), 2016, pp. 62-70.

[81] Treem, J.W., and P.M. Leonardi, "Social Media Use in Organizations. Exploring the Affordances of Visibility, Editability, Persistence, and Association", Communication Yearkbook 36, 2012, pp. 143-189.

[82] Trimi, S., and H. Galanxhi, "The impact of Enterprise 2.0 in organizations", Serv Bus 8(3), 2014, pp. 405-424.

[83] Vankatesh, V., M.G. Morris, G.B. Davis, and F.D. Davis, "User Acceptance of Information Technology: Toward a Unified View", MISQ 27(3), 2003, pp. 425-478.

[84] Volkoff, O., and D.M. Strong, "Critical Realism and Affordances: Theorizing It-Associated Organizational Change Processes", MISQ 37(3), 2013, pp. 819-834.

[85] Walsham, G., "Doing interpretive research", EJIS 15(3), 2006, pp. 320-330.

[86] Wang, T., C.-H. Jung, M.-H. Kang, and Y.-S. Chung, "Exploring determinants of adoption intentions toward Enterprise 2.0 applications: an empirical study", Behav Inform Technol 32(1), 2013, pp. 1-17.

[87] Ward, J., and E. Daniel, Benefits Management. Delivering Value from IS and IT Investments, John Wiley \& Sons, Chichester, 2006.

[88] Ward, J., and R. Elvin, “A new framework for managing IT-enabled business change”, ISJ 9(1), 1999, pp. 197-221.

[89] Wehner, B., T. Falk, and S. Leist, "What benefits do they bring? A case study analysis on Enterprise Social Networks", ECIS, (2017), 2069-2085.

[90] Wehner, B., C. Ritter, and S. Leist, "Enterprise social networks: A literature review and research agenda", Computer Networks 114(26), 2016, pp. 125-142.

[91] Williams, S.P., and P. Schubert, "Connecting industry: Building and sustaining a practice-based research community", HICSS, (2017), 5400-5409.

[92] Williams, S.P., and P. Schubert, "Designs for the Digital Workplace", CENTERIS, (2018).

[93] Wohlin, C., "Guidelines for Snowballing in Systematic Literature Studies and a Replication in Software Engineering", EASE' '14, (2014).

[94] Zeiller, M., and B. Schauer, "Adoption, motivation and success factors of social media for team collaboration in SMEs", ICKMKT, (2011).

[95] Zhang, J., Y. Qu, J. Cody, and Y. Wu, "A Case Study of Micro-blogging in the Enterprise: Use, Value, and Related Issues", CHI, (2010), 123-132.

[96] Van Zyl, A.S., "The impact of Social Networking 2.0 on organisations", Electron Libr 27(6), 2009, pp. 906-918. 